\title{
MARX, FREUD, FETICHE, CAPITALISMO \\ E A RELIGIÃo IORUBÁ
}

\author{
MATORY, J. Lorand. The Fetish Revisited: Marx, Freud, and the Gods \\ Black People Make. Durham: Duke University Press, 2018. 392p.
}

A centralidade da obra de James Lorand Matory nos estudos afro-americanos não pode ser desconsiderada. Não apenas a textura teórica revela um joeiramento crítico profundo, com uma capacidade de reflexão eclética e hermenêutica, como a riqueza do seu conhecimento particular e diversificado das religiões do chamado Atlântico Negro tornam suas obras de leitura obrigatória a todos que se dedicam ao estudo das religiões dessa geografia. Em uma obra anterior, Matory já havia expressado a importância do espaço circum-atlântico na emergência do nacionalismo iorubano (Lagosian Renaissance). ${ }^{1}$ Nela evidencia o papel de determinadas famílias da elite afro-atlântica na constituição de um conjunto de valores, bens e serviços que promoveram a

1 James Lorand Matory, Black Atlantic Religion: Tradition, Transnationalism, and Matriarchy in the Afro-Brazilian Candomblé, Princeton, NJ: Princeton University Press, 2005. consolidação daquilo que a literatura designa por "supremacia nagô" ou "nagôcracia", ao mesmo tempo que questiona a tradição cristalizada por Ruth Landes do matriarcado como padrão ortopráxico.

$\mathrm{Na}$ presente obra, Matory se propõe, como o título informa, a revisitar a emergência da categoria "fetiche" a partir dos seus maiores difusores no pensamento ocidental: Karl Marx e Sigmund Freud. Trata-se de uma proposta ambiciosa, que resulta numa obra de denso debate teórico, cuja riqueza, a meu ver, permite duas leituras concomitantes e, não necessariamente, justapostas. A primeira leitura da obra pode ser feita do ponto de vista da Antropologia do ritual e da história da Costa dos Escravos (a Costa da Mina luso-brasileira, litoral do golfo do Benim) enquanto lugar de encontros. Nessa leitura, Matory oferece uma entusiástica coleção de artefatos rituais, em particular o que no Brasil se chamam de "assentamentos", ou seja, terrinas, potes e outros contentores 
de pequenas dimensões nos quais são colocados e consagrados os objetos que representam a divindade. $\mathrm{Na}$ linguagem religiosa, o igbá Òrị̀à. Com referência a tais elementos, o autor lança um olhar sobre o papel do comércio africano interno e costeiro na composição da estética ritual, explicitando um cenário de natureza dinâmica que contesta quaisquer ideologias de "pureza" presentes no imaginário dos estudos afro-americanos $a b$ initio. Trata-se de uma característica fundadora do que ele denomina "religião indígena iorubá".

A segunda leitura da obra representa um desafio aos cânones filosóficos e teóricos ocidentais através da contestação dos postulados de Marx e Freud a propósito de "fetiche". Para ambos, os deuses do Atlântico Negro, bem como seus objetos rituais, em particular as imagens que os representam, seriam expressões religiosas e materiais de um pensamento "selvagem" e, por tal razão, representariam a antítese do pensamento "ideal", ou seja, da "civilização" representada pelos valores da burguesia branca ocidental. Com efeito, tais figuras rituais eram designadas, à luz do pensamento científico da época, de human-made gods, i.e., deuses criados pelos humanos. No entanto, ao invés de observarem tais divindades manufaturadas como objetos portadores de valor intrínseco e imbuídos do agenciamento de quem os manipula, ou seja, enquanto ativos sociais, religiosos e políticos que transcendem a sua dimensão material e se expressam como produtores de valor coletivo, Matory entende que Marx e Freud instrumentalizaram tais artefatos religiosos em função de suas próprias agendas teóricas. Ao afirmarem a falsidade de tais deuses manufaturados e, desse modo, colocando-os no papel de reflexos de uma cultura inferior, Marx e Freud recorreram ao que Matory chama de "ethnological schadenfreude", ou, basicamente, um estado de alegria etnológica ao dano feito a terceiros. Trata-se de um processo de transferência de características culturais (ou outras), negativas ou ambivalentes, de que se está sendo acusado, para outros grupos culturais ou sujeitos em situação social mais vulnerável, de modo a promover a auto ascensão na hierarquia social e estima moral, e desse modo provar seu direito a pertencer ao grupo dominante. No caso de Marx e Freud, a utilização desse procedimento permitiria deslocar o preconceito de que os judeus eram alvo para os africanos. Desse modo, Matory aplica a técnica freudiana a Freud e Marx. Com efeito, durante o século XIX o judaísmo era classificado como uma religião ilógica e repleta de superstições e, frequentemente, os judeus eram chamados de "pretos", "africanos", "primitivos" e "negros da Europa". Através de suas teorias, Marx e Freud teriam buscado, sobretudo, se libertar de sua posição racial ambígua enquanto judeus étnicos (não religiosos). Para Matory, Marx desconsiderou intencionalmente os escravos (não o assalariado na condição de dependência do 
detentor dos meios de produção, mas o escravo negro) na sua análise do trabalho assalariado, i.e., da relação estabelecida entre trabalhador que vende sua mão de obra e o detentor do capital que o contrata por um salário. No entender de Matory, ao aplicar o ethnological schadenfreude e buscando garantir os direitos do operariado branco no qual se reconhecia, Marx fez deste operariado a "verdadeira vítima" do capitalismo (p. 60). Nesse sentido, o negro escravo se tornou o antítipo dos trabalhadores brancos devidamente portadores de direitos (p. 33). É com esse diálogo com Marx que Matory encerra a primeira parte do seu livro.

Na segunda parte da obra, Matory desafia Freud, recorrendo, uma vez mais, à noção de "ethnological schadenfreude." Para o autor, Freud, assim como Marx havia feito para a sua teorização do salário ${ }^{2}$, elaborou suas reflexões, hipóteses e considerações sobre a condição humana a partir das suas ambivalências raciais e tentativas de mitigar o crescente antissemitismo na Europa do século XIX. A ambivalência racial e seu

2 O recorte desta resenha não se centra num debate - que poderia ser feito - entre as propostas marxistas e a interpretação de Matory. Tal não obsta, contudo, uma referência à teoria do salário de Marx, a qual dispõe sobre a produção de "mais-valia", ou seja, o diferencial entre o salário pago pelo patronato e a riqueza produzida pelo trabalhador, diferencial que corresponde, assim, ao lucro. Sugere-se a leitura de Alfredo Saad Filho, "Salários e exploração na teoria marxista do valor.", Economia e Sociedade, v. 10, n. 1 (2001), pp. 27-42. ethnological schadenfreude teriam ajustado as lentes pelas quais Freud observou e se apropriou dos "fetiches" africanos. Nas palavras de Matory, "O próprio gênero intersticial $^{3}$, orientação sexual e raça de Freud causou uma ambivalência que é bem explicada pela sua descrição dos fetiches mais poderosos e duradouros - ou seja, como objetos materiais hipercatéticos que encarnam a identificação do fetichista tanto com o castrado quanto com o castrador." (p. 166). Além do mais, o autor argumenta que tanto o "casaco" - que ele empenhou várias vezes - quanto a "fábrica" operam como fetiches na luta de Marx ao lado dos trabalhadores assalariados europeus contra o capitalismo e para serem aceitos na burguesia, quanto os anéis entalhados de Freud "encarnam o conflito entre o desejo dos judeus assimilados de se unirem à irmandade burguesa do estado-nação europeu" (p. 168).

A análise das ambivalências raciais de Marx e Freud (neste acrescem as sexuais) permite a Matory constituir um dos elementos mais determinantes da sua obra: a sentença da similitude entre deuses manufaturados e as teorias científicas ocidentais. Em seus próprios termos, "a teoria não é uma verdade desencarnada e universal, mas uma

$3 \mathrm{O}$ gênero intersticial corresponde a um meio termo entre identificações de gênero, um espaço que não se limita à excludência ou oposição entre gêneros masculino ou feminino. Cf. Kate Bornstein, Gender Outlaw: On Men, Women and the Rest of Us, Oxfordshire: Taylor \& Francis Ltd., 1994. 
criatura dialeticamente relacionada com o meio social, o meio material e os interesses materiais dos teóricos [...] Como o mais poderoso e espetacular dos 'fetiches' africanos, as mais poderosas e espetaculares teorias sociais europeias encarnam não só a ambiguidade social, mas também a ambivalência política e emocional dos seus criadores" (p. 39). Com efeito, podemos dizer que os altares afro-atlânticos (que são, a rigor, os deuses em si mesmos ${ }^{4}$ ) são instalados com objetos que possuem uma aura de valor e prosperidade, tais como búzios, dinheiro (e búzios eram moeda), bebidas alcoólicas europeias e missangas (que são chamadas em África de "sementes comerciais"). E, bem assim, no papel de elementos religiosos concebidos como autênticos, ordenam suas comunidades e incorporam um conjunto de valores éticos, estéticos e sociais que constituem o contrato social e a "religião civil"'. No mesmo nível, as teorias ocidentais incorporam uma soma de valores éticos, estéticos e sociais que, juntos, dão sentido às comunidades ocidentais e uma ilusão de

4 O conceito que pretendo utilizar é de gods-innerselves, conceito, todavia, de difícil tradução para português. A ideia central é que tais altares/assentamentos correspondem a deuses enquanto contentores, enquanto materialização ipso facto.

5 Cf. Jacob K. Olupona, "Orișa Oșun: Yoruba Sacred Kinship and Civil Religion in Oșogbo, Nigeria", in Joseph Murphy e Mei-Mei Sanford (orgs.), Osun Across the Waters: A Yoruba God in Africa and the Americas (Bloomington: Indiana University Press, 2001), pp. 46-67. universalidade. Destarte, as teorias não são mais do que "fetiches" aplicados por nossos padrões ocidentais de pensamento, que chamamos ciência, para dar sentido à nossa existência e traduzir a cultura do "outro". Nesse aspecto, merece nota o comentário de um aluno seu de Hong Kong que Matory publica. Como ele afirma, "as teorias, semelhantes aos deuses nos rituais afro-atlânticos, são feitas pelas pessoas", o que

não significa que elas, assim como os deuses, não sejam válidas ou reais [...] eles são reais no sentido de que envolvem uma troca de poder, e eles são capazes de afetar a maneira como pensamos e nos comportamos uns com os outros. Isso me faz lembrar de algumas experiências que tive na [Universidade] Duke. Depois de aprender sobre uma certa teoria que eles gostam ou concordam fortemente, como o super-homem de Nietzsche ou a teoria de Lacan do "real", alguns dos meus amigos aqui olhavam para tudo à sua volta através da lente dessa teoria e involuntariamente adotavam uma linguagem teórica na conversa diária, às vezes até com pessoas que não tinham ideia dessa teoria [...] Percebo que pode ser assim que a teoria, como fetiche em si, especialmente na academia, possa ter poder sobre nós, ainda que a intenção original deva ser a de utilizar a teoria na nossa compreensão do mundo. (p. 298).

Um outro olhar sobre a obra de Matory - nas margens da ambiguidade racial de Marx e Freud, i.e., enquanto judeus de tez escura, mas 
nascidos na Europa, e de como essa ambiguidade formatou suas teorias - nos conduz ao confronto entre duas formas diferenciadas de conceber e atribuir valor ao "outro". Como afirma Matory, "o Iluminismo e seus cientistas professaram uma relação de oposição e antagonismo com as religiões afro-atlânticas" (p. 28). Numa outra paisagem cultural e conceptual, encontram-se os deuses e sacerdotes afro-atlânticos. Para estes últimos, o "outro", i.e. o branco europeu e os demais povos vizinhos africanos, representam uma fonte de objetos poderosos, espíritos e deuses. Em meio ao comércio transatlântico e costeiro de escravos e outras mercadorias, muitas foram as mudanças introduzidas nas religiões afro-atlânticas. Um dos exemplos salientados por Matory é o de Ajé Sálúgá, a deusa do dinheiro e da riqueza (p. 197), cujo culto é criado a partir do princípio da troca e do lucro gerado pelo comércio atlântico, em meio ao qual os búzios e as conchas se tornam moeda. Com efeito, os altares de Ajé tornam-se metáforas do mercado atlântico, uma vez que os búzios e conchas vinham da região das Maldivas. A distância opera numa linha similar ao custo de produção, uma vez que quanto mais árduo for obter os búzios ou outros elementos ritualizados e incorporados nos deuses manufaturados, mais valor adquirem. Encontramos, portanto, a teoria da "mais-valia" no eixo religioso afro-atlântico.

Assim, tal como um trabalhador dá valor a um produto em função do tempo gasto na sua produção
(Marx), o sacerdote dá valor ao deus feito pelo número de elementos montados no vaso/pote e seu valor econômico e comercial/de troca, como contas, búzios ou garrafas de bebidas alcoólicas.

Nesse sentido, a leitura do livro de Matory pode ser uma experiência chocante para os militantes negros e puristas afro-religiosos, particularmente no Brasil, onde antropólogos como Roger Bastide e outros ajudaram a criar uma ideologia de "pureza africana" que, juntamente com os movimentos negros, produziu uma utopia de negritude liberta da influência branca.

Longe das ideologias de "pureza" e "autenticidade" fabricadas em meio às experiências diaspóricas e seus cruzamentos com a academia, o espaço afro-atlântico animou-se no comércio. A incorporação de elementos chineses (p. 203, p. 231), "contas venezianas e boêmias, gin escocês, schnapps ${ }^{6}$ holandeses e cerveja, perfumes e champanhe franceses, búzios e conchas das Maldivas, espelhos, cetim, lantejoulas e terrinas de sopa" (p. xix) fazem parte deste processo de dar valor às coisas estrangeiras que se incorporam nos altares e rituais dos deuses afro-atlânticos. Como defende Matory, a negritude dos vasos onde são depositados os búzios nos altares afro-atlânticos e a brancura desses búzios parecem expressar uma alegoria e comemoração da relação intercontinental produtora desse

6 Bebida destilada. 
eixo. Ademais, a própria forma dos altares afro-atlânticos reforça a herança do comércio afro-europeu, uma vez que as terrinas parecem representar os navios negreiros. Tais altares resumem a confiança no valor da produção e das trocas, adquirindo tanto mais valor quanto mais diferenciados e distantes forem os parentes, grupos étnicos e eras de sua proveniência. Tal ideia é evidente tanto na África, quanto em Cuba, no Brasil ou no Haiti. Nesse sentido, é possível afirmar que o capitalismo é a base da dinâmica das religiões afro-atlânticas, e que a noção de troca é absolutamente essencial, uma troca não apenas entre deuses e humanos, mas sobretudo entre humanos em favor da constituição de seus deuses.

A presente obra dá forte contributo para o cenário afro-brasileiro, onde as questões de autenticidade africana são prementes, ao evidenciar o sentido contrário de tal ideologia, enfatizando a dimensão híbrida das culturas afro-atlânticas. Tais dados não são novos. Os leitores familiarizados com a bibliografia anglófona sobre a região bem conhecerão o trabalho de Olabiyi Yai a propósito das categorias de pensamento introduzidas pelo cristianismo na região fon do Daomé e a construção da teologia monoteísta de Mawu a Lisa. ${ }^{7}$ Luís Nicolau Parés, em sua mais recente obra sobre o culto

7 Olabiyi Babalola Yai, "From Vodun to Mawu: Monotheism and History in the Fon Cultural Area", in Jean-Pierre Chrétien (org..), L'Invention religieuse en Afrique: Histoire et religion en Afrique noire (Paris: Karthala, 1993), pp. 241-265.
Vodun, também aponta no mesmo sentido, ratificando a prática de incorporação dos elementos religiosos alienígenas na região do Daomé. ${ }^{8}$

Discutindo a natureza daqueles deuses feitos pelo homem - aqui cruzando-se com o artigo de Karin Barber, "How man makes god in West Africa" - e, ainda que não o mencione, Matory chega à teoria do "dom" de Mauss, argumentando sobre a dependência mútua entre deuses "feitos" e adoradores, uma relação que "inclui alimentar o deus $[\ldots]$ e pedir-lhe favores que resultam em obrigações recíprocas" (p. 173). Além disso, Matory alerta para o fato de que os sacerdotes afro-atlânticos reconhecem a manufatura/fabricação de seus deuses através de vasos, contas/missangas, artefatos e outros elementos, tanto quanto pela iniciação dos sujeitos, um processo que $f a z$ a divindade (șe Òrìsà̆hacer el santol fazer o santo). No entanto, é evidente a necessidade de estar atento à distância entre a linguagem afro-atlântica e as categorias da linguagem ocidentais (v.g. p. 282). Quando se trata de traduzir culturas, a perda e os constrangimentos são enormes (p. 253). Como lembra Thompson, enquanto o pensamento ocidental se estabelece na exclusão, o pensamento africano, por oposição, apresenta o princípio

8 Luís Nicolau Parés, O rei, o pai e a morte: a religião vodum na antiga Costa dos Escravos na África Ocidental, São Paulo: Companhia das Letras, 2016.

9 Karin Barber, "How Man Makes God in West Africa: Yoruba Attitudes Towards the Orisa", Africa, v. 51, n. 3 (1981), pp. 724-745. 
da concordância entre elementos opostos ou contraditórios. ${ }^{10}$

Os deuses são concebidos como anteriores à humanidade, mas isso não significa que não sejam feitos por seres humanos. A noção desse paradoxo encontra-se presente na fala dos atores religiosos entrevistados pelo autor, representando um desconforto e um desafio hermenêutico para os mesmos. Com efeito, eles reconhecem que os deuses são feitos, tanto no sentido material de serem manufaturados, quanto no sentido humano de que a iniciação $f a z$ a divindade existir no corpo do neófito. Ao mesmo tempo, estão avisados das teorias de falsa agência e valor dos "fetiches", jogando com as palavras entre produção, agência e simbolização, e resolvendo o paradoxo com o fato de que os altares ajudam a invocar a energia (àsẹ) da divindade.

O livro de Matory é um longo ensaio, cheio de detalhes relevantes

10 Robert Farris Thompson, Guest Lecture on Creole Culture in NIH Seminar on African Derived Music, Yale University, 1989, apud Frank A. Salamone, "A Yoruba Healer as Syncretic Specialist: Herbalism, Rosicrucianism and the Babalawo", in Sidney M. Greenfield e André Droogers (orgs.), Reinventing Religions: Syncretism and Transformation in Africa and the Americas (Nova York/Oxford: Rowman \& Littlefield Publishers, 2001), pp. 43-53. sobre a atribuição de valor à linhagem e ao matrimônio, a forma com a família iorubá se estrutura entre "mais velhos" e "mais novos" e não a partir do gênero dos sujeitos, o equilíbrio entre masculino e feminino presente nos pássaros das coroas dos reis, e o fato do monarca se apresentar como "pai" para o seu povo e "esposa" para a divindade tutelar da cidade. É uma obra que enfatiza os altares afro-atlânticos como representação da "mais-valia" do comércio, das trocas, do espírito do capitalismo como produção e aquisição de bens que fazem tais altares (fetiches) - porquanto objetos e elementos de terras distantes, difíceis de obter e de custo elevado, são concebidos como portadores de "mais-valia", de valor acrescentado. No presente livro, Matory retoma aspetos de seu Black Atlantic Religion ligados à ritualidade iorubana, e os coloca em confronto com Marx e Freud, convidando-os a dançar, entre valsas vienenses e batuques africanos, apresentando toda uma partitura feita com noivas afro-atlânticas, equitação e seus significados rituais, coroas de monarcas africanos, vasos, terrinas, missangas, búzios e conchas, bebidas alcoólicas, seus próprios piano, charutos, anéis entalhados, casacos e ambivalências.

João Ferreira Dias

Instituto Universitário de Lisboa (ISCTE-IUL) joaoferreiradias@outlook.pt 